\title{
Editorial
}

\section{La formación clínica de las enfermeras y la figura del tutor en el siglo XXI, un reto para los docentes}

\section{The clinical training of nurses and the tutor in the XXI century, a challenge for educators}

O ensino clínico de enfermagem eo tutor no século XXI, um desafio para os professores

\author{
$\mathrm{M}^{\mathrm{a}}$ Carmen Solano Ruiz ${ }^{1}$ \\ ${ }^{1}$ Profesora Titular Facultad Ciencias de la Salud de la Universidad de Alicante.
}

Cómo citar esta editorial en edición digital: Solano Ruiz, Ma C. (2012) La formación clínica de las enfermeras y la figura del tutor en el siglo XXI, un reto para los docentes. 16, 34. Disponible en: http://dx.doi.org/10.7184/cuid.2012.34.01>

Correspondencia: Departamento de Enfermería. Universidad de Alicante. 03080, Alicante. España.

e-mail: Carmen.solano@ua.es.

En la actualidad, nos encontramos sin duda alguna, en un momento de gran fervor en lo concerniente a la universidad europea ocasionado principalmente por la confluencia simultánea de dos cambios sociales de gran calado; por un lado, la participación en el Espacio Europeo de Educación Superior (más conocido como tratado de Bolonia) y por el otro lado, por la creciente presión ejercida por la sociedad y sus instituciones sociales y políticas para que la universidad se convierta en el organismo impulsor de los distintos tipos de cambios a los que la sociedad actual debe hacer frente. Con el establecimiento de la Declaración de Bolonia (1999) se sentaron las bases para la construcción de un "Espacio Europeo en Educación Superior"; un espacio compartido y organizado de acuerdo a unos principios basados en la calidad de la enseñanza, la movilidad tanto del profesorado como del alumnado, el respeto a la diversidad cultural en las aulas y la competitividad de mercados.

Los principales cambios propuestos se cen- tran en tres pilares básicos: modificación de las metodologías docentes, revisión y adaptación de los contenidos de las titulaciones y definir claramente el perfil $u$ orientación de los nuevos titulados (Maciá et al, 2006). En definitiva, se trata de un cambio de paradigma educativo, una nueva reconceptualización que debe realizar un giro en el enfoque educativo tradicionalmente orientado a los docentes hacia un enfoque más participativo y responsable de los estudiantes universitarios. Esta forma de entender la enseñanza condiciona de una manera directa tanto la formación teórica como la formación práctica impartida en las distintas titulaciones, sobre todo y de manera muy especial en aquellas titulaciones vinculadas al área de ciencias experimentales donde las instituciones sanitarias juegan un papel primordial.

La formación de enfermeras no supone una práctica sencilla, debido principalmente a las peculiaridades del contexto social y sanitario donde se desarrolla. Dada la complejidad del 
proceso, las enfermeras asistenciales deben asumir un rol preponderante en la formación de alumnos, siendo imprescindible dotarles de voz y autoridad durante todo el proceso de formación llevado a cabo, estableciendo de esta manera la visibilidad de las mismas que hasta estos momentos ha sido escasamente reconocida (Pérez et al, 2002)

Son muchas las denominaciones que se le atribuyen a esta labor en función de su cometido, términos como mentor, counselling, coaching y tutor han sido utilizados de manera indiscriminada en la literatura enfermera. Siendo el vocablo "tutor" el término más empleado para definir las funciones que se le atribuyen a las personas implicadas en el acompañamiento, consejo, orientación y evaluación de los alumnos durante sus prácticas clínicas.

Si la figura de tutor es diversa mucho más difícil se hace la identificación de sus funciones y el rol a desempeñar, entendiendo ésta como el conjunto de fases que debe de cumplir el profesional de enfermería en relación al aprendizaje práctico del estudiante. Dentro de las funciones que se le asignan, el tutor debe estar preparado para afrontar y reconducir todo tipo de situaciones que se les planteen a los alumnos, desde las más convencionales y rutinarias, hasta las emergentes más inadvertidas e imprevisibles invitando a la reflexión del proceso. El tutor no sólo tiene funciones evaluadoras, también debe orientar la acción de los alumnos mediante el establecimiento del un clima educativo donde la comunicación fluya sin problemas.

En este sentido, se hace necesario la creación de un compromiso firme por parte de las distintas instituciones que entran en escena, como son las sanitarias y académicas, potenciando sus fortalezas y profundizando en la relación de pertenencia e identificación entre docentes y profesionales asistenciales, con la finalidad de garantizar unas altas cotas de calidad en la enseñanza de los alumnos para la obtención del título de Grado en Enfermería.

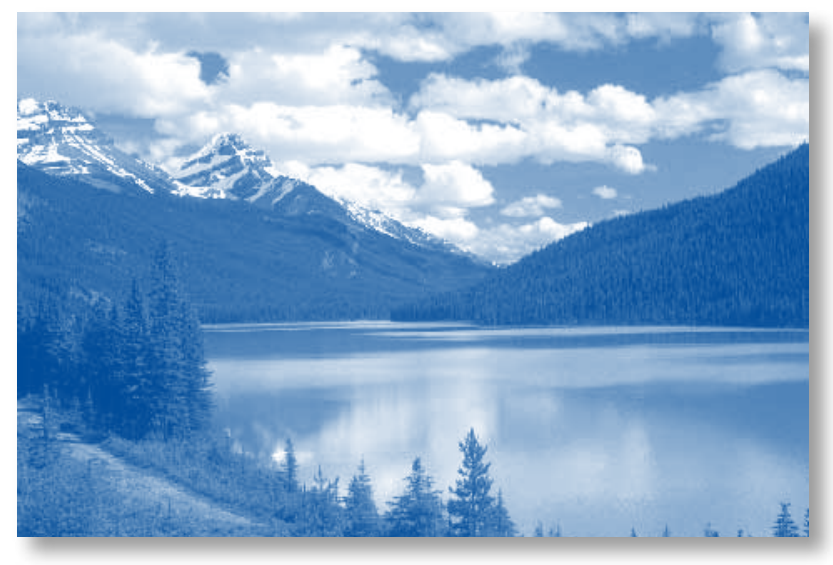

